\title{
ePortfolio: A Descriptive Survey for Contents and Challenges
}

\author{
http://dx.doi.org/10.3991/ijet.v11i01.4900 \\ S.R.H. Abd-Wahab, A. I. Che-Ani, S. Johar, K. Ismail, M. Z. Abd-Razak \\ Universiti Kebangsaan Malaysia, Bangi Sengalor, Malaysia
}

\begin{abstract}
Online learning is currently garnering increasing interest. Through the Internet, all available data can be shared to anyone without limited accessibility. ePortfolio is one of the media for students and lecturers to share their knowledge online. Students can upload and share their works, and lecturers can access the works of students anytime and anywhere as long as they remain connected to each other. This learning process gives students the freedom to show their ability and skills without meeting face to face. In literature, ePortfolio has contributed numerous advantages to students and lecturers in terms of the competency, marketability, self-confidence, and visibility of the students. This paper analyzes the development of ePortfolio contents to ensure the reliability of the instrument used. Furthermore, the challenges to implement ePortfolio in the learning system in Malaysia are determined. A total of 100 respondents, who are educators and students from public higher education institutions in Malaysia, participated in the Google survey form to share their perspective on the development of ePortfolio and the challenges of its implementation in the learning system. The majority of the respondents gave positive feedback on the development of ePortfolio as one of the holistic approaches to evaluate a student's knowledge and skills.
\end{abstract}

Index Terms-ePortfolio; Development contents; Challenges; Implementation

\section{INTRODUCTION}

In today's borderless world, information communication technology (ICT) is one of the virtual tools that is being used globally. Anyone can access all types of information online because of the rapid development of ICT. People can communicate with one another without meeting face to face as long as they are connected through the Internet. This facility also influences the business, education and other sectors. For example, businessmen can communicate with their business partners even though they are thousand miles away from each other. They can use video conference to handle meetings and electronic mail to send information. These virtual tools give them flexibility and allow them to save cost and time in operating their business.

The rapid development of ICT affects the education sector by enhancing its accessibility, appeal, and flexibility. Learning has become interesting and exciting. The development of ePortfolio in the education system attracts students to learn and explore their ability to gain knowledge. Through the ePortfolio system, students can upload their works to share their knowledge and skills online. Often, students do not have the self-confidence to show their talent during face-to-face learning. They are shy to communicate in a real meeting. This challenge makes them less productive in their learning. Having access to ePortfolio can increase student motivation and selfconfidence. Students can also have a forum with their friends and lecturers to share their opinions and knowledge on their subjects.

This paper discusses the development content of ePortfolio and addresses the challenges of implementing ePortfolio in educational institutions through a survey of students and lecturers from public higher education institutions in Malaysia. The findings reveal the most critical items that should be included in ePortfolio content. The challenges in implementing ePortfolio are also highlighted.

\section{A. Development of ePortfolio Contents}

At present, the development of ICT is widely spread across the globe. The emergence of social media, such as Facebook, Instagram, and Twitter, makes the separation of all types of information easy and quick. This development influences the culture of human interaction [1]. People prefer to communicate in the virtual world rather than in a real meeting. Online information sharing is at their fingertips. Online systems make people feel connected to one another easily although they live apart. Furthermore, searching for information, contacts, old friends, and so on is effortless. This scenario makes people feel that every moment of their lives is valuable.

In education, ICT creates ePortfolio as a platform to enhance the learning process. Hall [2] pointed that ePortfolio play a key role to impetus teaching and learning and increased the attention to engaged in research and teaching. Moreover, This medium enables lecturers and students to share their notes and works online. For example, lecturers can upload notes and assignment to students online. Then, students can submit their assignments online through ePortfolio. Learning becomes easy because it can be done anytime and anywhere. Universities in the United States have already implemented the usage of ePortfolio in their education system. ePortfolio is different from Elearning in terms of accessibility. E-learning only enables information sharing between lecturer and students, but the function of ePortfolio is more widespread. Statistics indicate that the number of ePortfolio users nearly doubled from 2011 to 2012 [3]. In a nutshell, ePortfolio is more efficient than traditional portfolios as tools to be stored and tracked for long periods of time [4].

Portfolio is defined as the compilation of a student's work over a period to access their performance progress. The traditional method of producing a portfolio is binding a compilation of printed papers. Currently, ePortfolio done 
PAPER

EPORTFOLIO: A DESCRIPTIVE SURVEY FOR CONTENTS AND CHALLENGES

through ICT is becoming popular [5]. Previous journals included several definitions of ePortfolio. Lorenzo and Ittelson [6] mentioned that ePortfolio is a digital collection of artwork, artifacts, paperwork, and accomplishments to recognize the existence of an individual, group, community, or institution. From an education perspective, ePortfolio is a platform for students and lecturers to present their ability to share knowledge and information. Therefore, ePortfolio can demonstrate the performance and achievement of a student [7] and [8]. A compilation of student works can be retrieved on a website or other electronic media comprising electronic graphics and multimedia that enhance interest on and excitement for the work [6]. Hence, ePortfolio is a tool to support and document students' personal, professional and intellectual development [9].

The content of ePortfolio must support the development and learning of the student, assessment of the student's learning, and marketability [8]. ePortfolio is different from E-learning; The ePortfolio system is more public and can be assessed by anyone in the virtual world without the consent of the individual. Viewers of any portfolio can vary and be infinite [7]. Therefore, all information that should be shared in an ePortfolio must be suitable for public viewing with specific goals (Jenson, 2011). Lorenzo and Ittelson [6] mentioned that the six major contents of ePortfolio include the following:

i. Plan educational programs

ii. Document knowledge, skills, abilities, and learning

iii. Track development within a program

iv. Find employment

v. Evaluate a course

vi. Monitor and evaluate performance

The emergence of ePortfolio can increase the value of a student's potential in learning. To have a good ePortfolio, a student needs to demonstrate only the required artifacts [10]. The artifacts must be able to present the potential academic performance and marketability in the workforce of a student [11]. For example, an assignment or artwork marked high needs to be included in the ePortfolio, whereas the lowest marked assignment or artwork should be excluded. The purpose is to increase the marketability of a student's performance so that he/she can find a job easily after graduation. An ePortfolio can enhance the first impression of an employer; students who have a good ePortfolio can be hired. The survey among employers conducted by Hart Research Associate [12] indicates that $83 \%$ of employers believe that an ePortfolio can indicate the skills and competency of a job applicant. This statement supported by Whitworth [13] stated that ePortfolio is an essential element for success in the areas of employment and career advancement.

Therefore, students must select a core course as a priority to upload the contents of their ePortfolio. For instance, most of the works of architecture students are related to design. Thus, an architecture student must upload his/her artworks that have good marks as the main priority contents in his/her ePortfolio, which is important when he is applying to be an architect. When employers are viewing an ePortfolio, they want to see the main core course before they look for the extracurricular activities. Figure 1 presents the sample content of an ePortfolio of an architecture student in Clemson University. The main con-

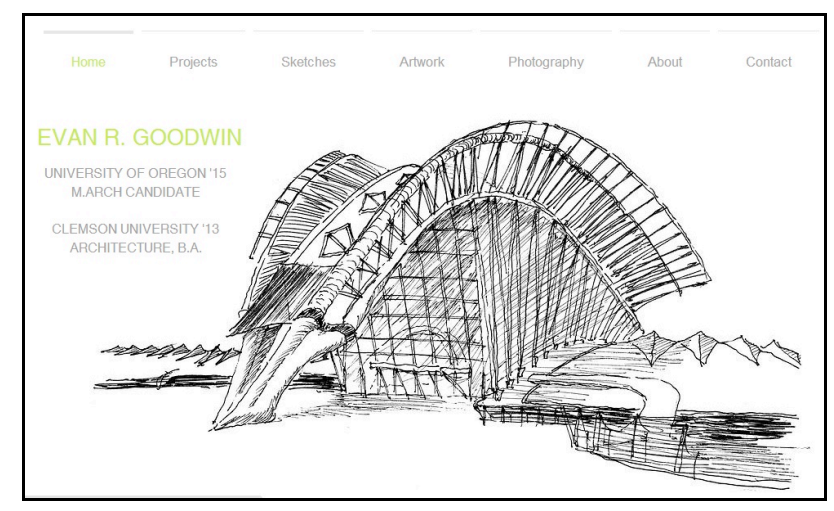

Figure 1. ePortfolio of an Architecture Student

(http://www.evanrgoodwin.com/) (Accessed on 14 May 2015)

tent of the ePortfolio consists of projects, sketches, artwork, and photography. All these contents are the priority artifacts that should be included in the ePortfolio of an architecture student.

For other students from different background courses, the ePortfolio content may consist of three sections, namely, academic (core course), extracurricular activities (soft skills), and experience (practical training) [14]. Materials that need to be included in the academic section are mostly works related to the core course. Then, activities that enhance their competency and soft skills can be included as the extracurricular activities [15]. Finally, their experience in their practical training can be included in the experience section. Briefly, the inclusion of materials that may reduce a student's marketability must be avoided in the ePortfolio.

\section{B. Challenges in Implementing ePortfolio}

Implementing ePortfolio in learning has several advantages and challenges. Jarrott and Grambrel [8] mentioned that ePortfolio is the latest technology that can enhance the technology skills of a student, aid in future job hunting, and evaluate skill performance and selfconfidence. All of the contents in the ePortfolio can be a source of evidence to improve a student's future career development [16]. According to the survey by Hart Research Associate [12], 95\% of employers prefer to hire candidates that have skills that can contribute to the innovation of the company. Thus, the ePortfolio must be interactive and filled with exciting knowledge to be shared in the future [17]. However, the challenges of creating and implementing a good ePortfolio are several. Accessibility is not limited, and thus students need to be careful in selecting materials to be uploaded in their ePortfolio. An unnecessary material can reduce the marketability of a student if uploaded. Thus, students are responsible for their own ePortfolio and the information it contains [18].

In addition, Peacock et al. [19] noted that learners continue to prefer the conventional portfolio method, which involves the compilation of printed papers. They do not want to use ePortfolio as a springboard for their development on meta-cognitive skills and future career development. The learners shared that difficult accessibility to the Internet at their place makes connecting with their ePortfolio difficult most of the time. Danowitz [20] also mentioned that uploading large files into an ePortfolio is difficult and time consuming. Moreover, users have to protect their password for security purposes and to always back up their files because of server 
problems. Certain students are also forced by their lecturer to upload all their works into an ePortfolio. They do no realized the benefits of having an ePortfolio by themselves. Thus, ePortfolio is not yet a popular platform in education if compared with other social sites, such as Twitter, Instagram, and Facebook.

\section{RESEARCH METHOD}

The research strategy adopted in this paper is quantitative in nature, with the data collected by using a Google survey form. The online survey focuses on the Malaysian practices among educators and students at public higher education institutions in Malaysia. The purpose for conducting this survey is to analyze the respondents' perspective on ePortfolio as one of the latest tools for teaching and learning. The Google survey form is formulated based on the respondents' perspective on ePortfolio, such as the development of the ePortfolio contents; the requirements of the ePortfolio criteria, grading, and assessment method; and the challenges that may be encountered in ePortfolio implementation. Responses are scored according to the Likert scale. Three types of Likert scale are used to describe the meaning of the value based on the questions raised. To evaluate the perspective on ePortfolio and the grading system as well as assessment method, the range of Likert scale used comprises $5=$ Strongly Agree, $4=$ Agree, $3=$ Neither Agree or Disagree, $2=$ Disagree, and 1 $=$ Strongly Disagree. By contrast, to evaluate the development of the ePortfolio contents and the requirement of the ePortfolio criteria, the range of Likert scale used includes $5=$ Essential, $4=$ High Priority, $3=$ Medium Priority, 2 = Low Priority, and $1=$ Not a Priority. Furthermore, to evaluate the challenges that may be encountered in ePortfolio implementation, the Likert scale consists of $5=$ Major Challenges, $4=$ Moderate Challenges, $3=$ Neutral, $2=$ Minor Challenges, and $1=$ No Challenges. The horizontal bar chart and pie chart present the analyzed data with rectangular bars and lengths proportional to the values they represent.

\section{ANALYSIS AND DISCUSSION}

\section{A. Respondents}

The analysis provided by the Google survey form indicated that 100 respondents, who are educators and students, participated in the survey. Figure 2 illustrates that most of the respondents who participated were students $(79 \%)$, followed by the academic staff $(20 \%)$. The rest of the respondents were from the technical staff $(1 \%)$.

The respondents came from various academic backgrounds, including science program, management program, engineering program, social science program, information technology program, and built environment program. Based on Figure 3, most of the respondents came from the engineering program $(76 \%)$, followed by respondents from the built environment program (12\%), the management program $(6 \%)$, the social science program $(3 \%)$, the science program $(2 \%)$, and lastly by the information technology program (1\%).

The survey asked respondents about their interest in social media interaction. Social media today comprise several platforms, such as webpage, Instagram, Twitter, Facebook, blog, website, and email. The survey question identifies the level of respondent interaction using social

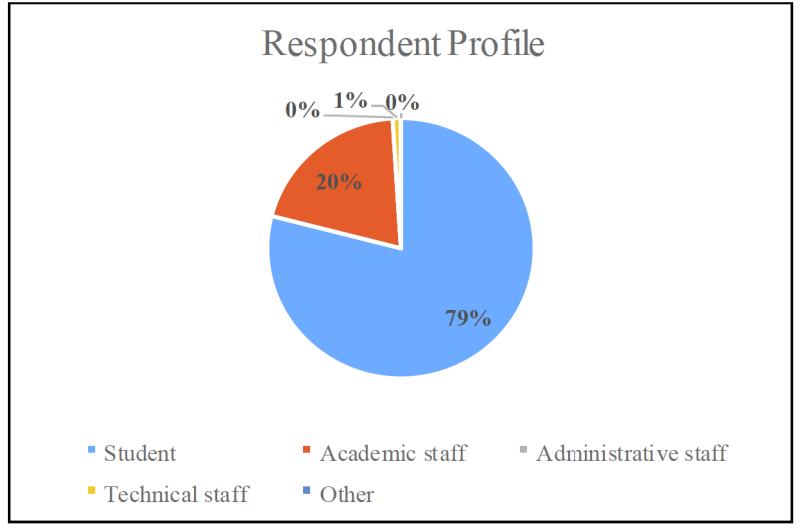

Figure 2. Respondent Profile

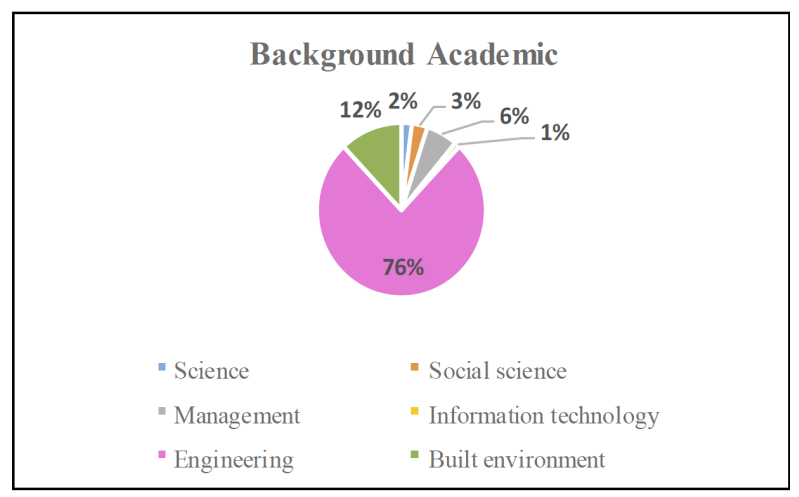

Figure 3. Academic Background of Respondents

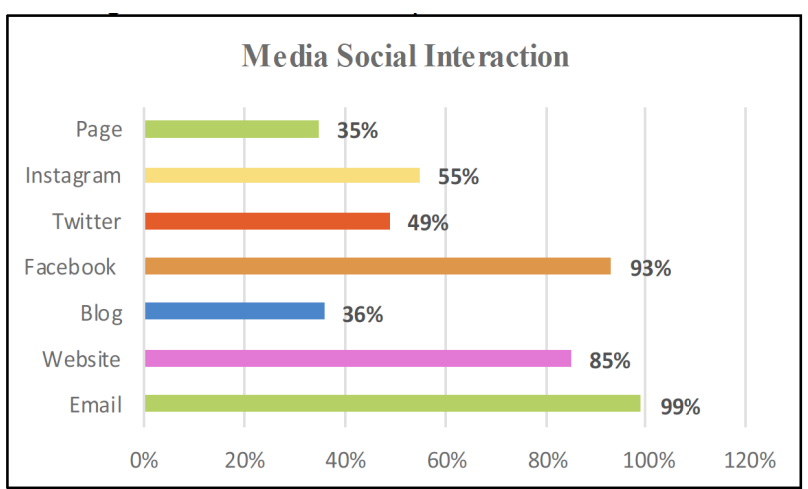

Figure 4. Interaction of Respondents with Social Media

media. Rationally, the interaction of people using social media signifies their awareness on the rapid development of ICT in their social environment. Figure 4 demonstrates that the majority of respondents are aware of the development of ICT by having their own social media accounts. The analysis indicates that the majority of respondents (93\%) have their own email and sign in with Facebook. People nowadays prefer to communicate in the virtual world rather than in a real meeting. Furthermore, $85 \%$ of the respondents have their own website. Respondents use other social media, such as Instagram (55\%), Twitter (49\%), their own blog (36\%), and their own webpage (35\%), that is, via Google, Weebly, Wordpress, folio, and so on. Therefore, the majority of the respondents are ICTliterate. The emergence of ICT in educational institutions cannot possibly lead to the creation of ePortfolio as a platform to enhance academic learning. 
Considering that the majority of the respondents are ICT-literate, they also have their own gadgets to access information available online. Based on Figure 5, smartphone has the highest number of users $(55 \%)$, followed by laptop or notebook $(35 \%)$, and then desktop (7\%) and tablet (3\%). Therefore, by using these gadgets, all the information shared online is at their fingertips.

Based on the survey, most respondents prefer being connected to the Internet. Figure 6 illustrates that $65 \%$ of the respondents are constantly connected to the Internet, whereas $48 \%$ have their own data subscription. Therefore, the online system makes people feel connected to each other although they live apart. Searching for information, contacts, old friends, and so on is also effortless. This scenario makes people feel that every moment of their lives is valuable.

\section{B. The Development of ePortfolio - Advantages of ePortfolio}

Jarrot and Gambrel [8] stated that the development of an ePortfolio must support the student's development and assess his/her learning and marketability. From the paper's analysis, the development of ePortfolio can enhance the visibility, self-confidence, marketability, and competency of the student. Figure 7 illustrates that $29 \%$ of the respondents strongly agree that ePortfolio can increase student visibility in their learning process, whereas the majority, which is $66 \%$, agree that it can increase the marketability and self-confidence of students. Thus, ePortfolios are a platform to demonstrate student achievements (i.e., beyond the reach of the teacher) because the traditional assessment system (i.e., grades and test score) provides insufficient evidence [8]. Moreover, ePortfolio provides students creative options to transfer their experiences to interactive and meaningful displays of performance. "Displays of performance" indicates the students' soft skill level, which determines their success in job application [21]. Students who want to succeed must learn to develop their soft skills. However, only $5 \%$ of the respondents disagree that ePortfolio can increase the competency of students, and $1 \%$ strongly disagree that ePortfolio can increase the marketability of students.

\section{Perspective of ePortfolio}

The survey results indicate different perspectives on ePortfolio in educational institutions. Figure 8 presents that $45 \%$ of respondents (45\%) agree that ePortfolio must be graded, and $53 \%$ propose an ePortfolio award. Students are often motivated by grades and awards rather than by simply learning to achieve the ultimate goal, that is, graduation [18]. This mindset causes students to pursue only good academic results but ignore the development of soft skills, which are very important in the working environment [21]. A total $48 \%$ also agreed that ePortfolio should include only key learning materials. Tolley [10] mentioned that the selected artifacts must be a collection of works that reflect the students' potential in terms of academic performance and their marketability in workforce. Therefore, only the best materials (from the student assignments) and highly influential involvements in extracurricular activities should be included in the ePortfolio. Uninfluential artifacts must not be included in the ePortfolio because these reduce the marketability of the students. Moreover, $62 \%$ of the respondents suggest a mentormentee concept to encourage students to develop their

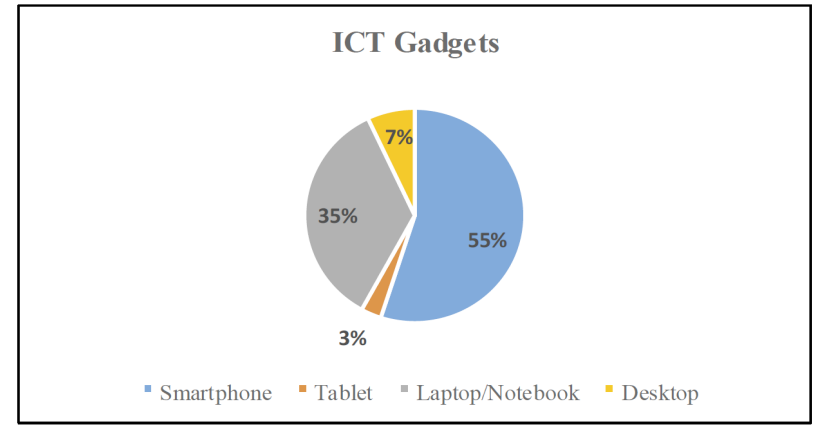

Figure 5. Respondent Preference on ICT Gadgets

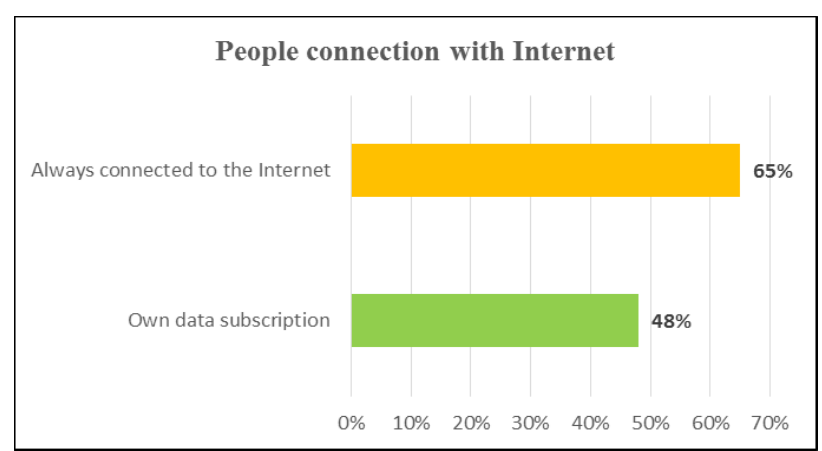

Figure 6. People's Internet Connection

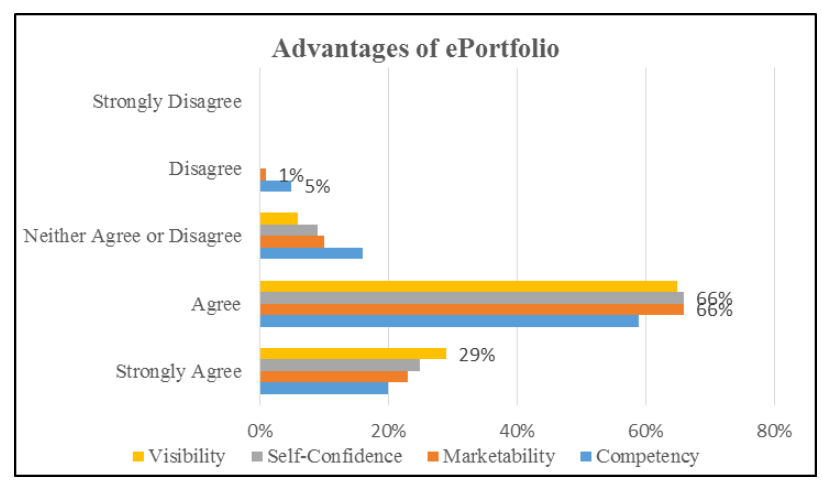

Figure 7. Advantages of ePortfolio

ePortfolio. To produce a good and interesting ePortfolio, students must be guided correctly from the time of their enrolment in universities.

ePortfolios also operate as a highly influential practice that provides students and educators with an assessment tool to improve academic success [5]. From the survey, $62 \%$ agree that requiring an ePortfolio can ensure the success of the ePortfolio system, $66 \%$ grant that making an ePortfolio is one of the learning agility scenarios that inspire students to develop their skills slowly, and $67 \%$ concur that lecturers need to have their own ePortfolio to encourage students to create their own ePortfolio. Therefore, the analysis signifies that having their own ePortfolio can ensure the students' learning success.

\section{Content Development of ePortfolio}

The content development of an ePortfolio is one of the important aspects that require attention. A good content development of an ePortfolio ensures the success of the ePortfolio system. Figure 9 demonstrates that $65 \%$ of the respondents prioritize academic core course materials because the collection of core course materials reflects a 
student's potential in terms of academic performance and marketability in the workforce. Therefore, only the best assignments in their academic core course should be placed in the ePortfolio of students. The survey results also note that $39 \%$ insist that real industry experiences related to the academic program should be included in the ePortfolio. This content is an added value that illustrates the students' competency and skills, which increase their marketability when competing for a place in the workforce. Moreover, the Citra education domain may have a small effect on the success of an ePortfolio; only 54\% state that it warrants medium priority in terms of content that must be included in the ePortfolio.

\section{E. Criteria of ePortfolio that Need to be Graded}

Several criteria of ePortfolio must be graded to ensure the success of the ePortfolio system. From the survey, Figure 10 presents that the selection of artifacts $(51 \%)$ requires high priority. The right selection of artifacts in an ePortfolio can help increase the marketability of a student [7]. By contrast, those who insisted that the criteria of reflection or critique should be of high priority comprise $48 \%$. The criteria of reflection must be graded because ePortfolio can encourage students to be reflective when constructing their own ePortfolio [22]. This reflection is important in the learning process because students can integrate their learning experience and find meaning in them [6], [23], and [24]. The use of multimedia (48\%) followed by hyperlink (45\%) are also essential criteria that should be graded to ensure an interactive and accessible appearance of ePortfolio. Moreover, Lorenzo and Ittelson [6] agreed that to enhance the appearance of ePortfolio, electronic media consisting of text-based, graphic, or multimedia elements should be used. Then, criteria for citation (41\%), layout and readability (56\%), and quality of writing and proofreading $(49 \%)$ are of high priority to ensure the originality of the ePortfolio created. Issues of plagiarism and typing and grammatical errors can also be minimized when these criteria are graded. Finally, the use of cloud computing (38\%) is only of medium priority in the criteria that should be graded.

\section{F. ePortfolio Assessment Method}

This survey also identifies the lecturer's assessment method of ePortfolio that the respondents agree with. Figure 11 indicates that $64 \%$ (i.e., the highest percentage) of the respondents agree with evaluating through the virtual environment as the assessment method of ePortfolio by the lecturer. This percentage is followed by $59 \%$ for the standardized rubric or scoring system and 53\% for the use of infographics. Respondents who neither agree nor disagree with the face-to-face method comprise $41 \%$. Finally, the majority of the respondents (31\%) disagree with the method of unstructured assessment, which is up to the lecturer. ePortfolio can be assessed online anytime and anywhere; therefore, respondents consider that an improved ePortfolio assessment must be conducted through a virtual environment. Consequently, lecturers feel free to view the ePortfolio at their convenience. A standardized rubric or scoring system to assess ePortfolio can also prevent lecturer bias against students. Hence, a suitable assessment method of ePortfolio is important to determine the success of the ePortfolio system [25].

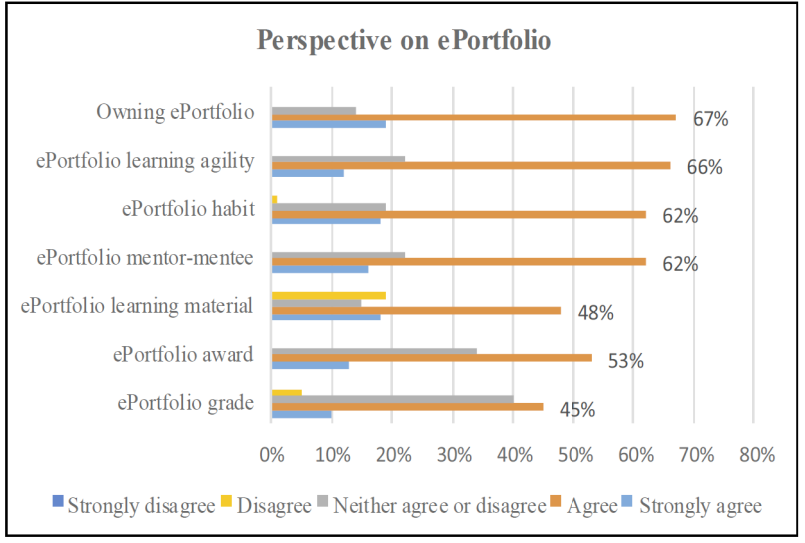

Figure 8. Perspective on ePortfolio in the Learning Process

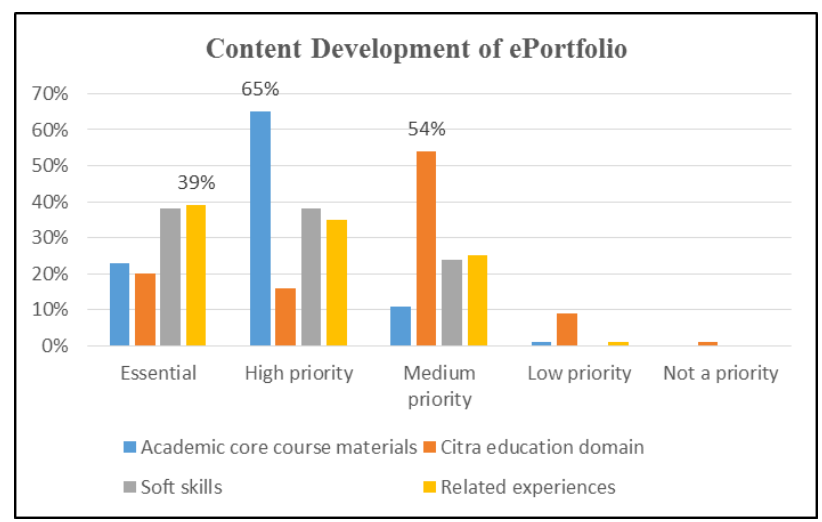

Figure 9. Content Development of ePortfolio

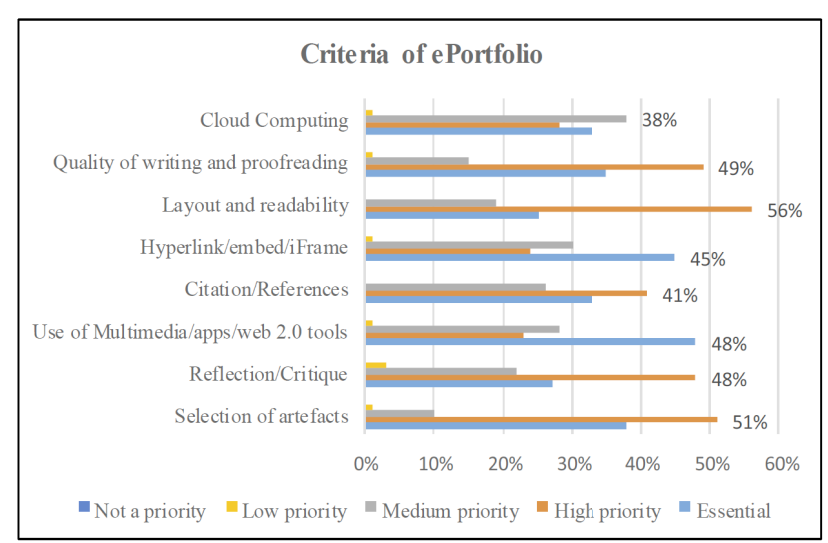

Figure 10. Criteria of ePortfolio that Need to be Graded

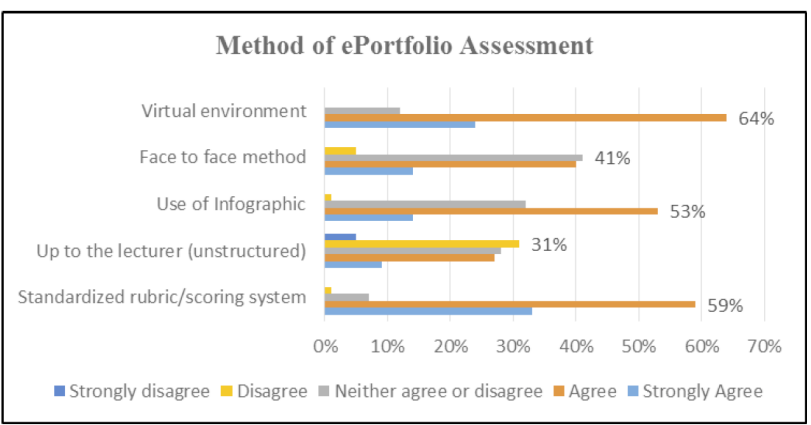

Figure 11. ePortfolio Assessment Method by the Lecturer 


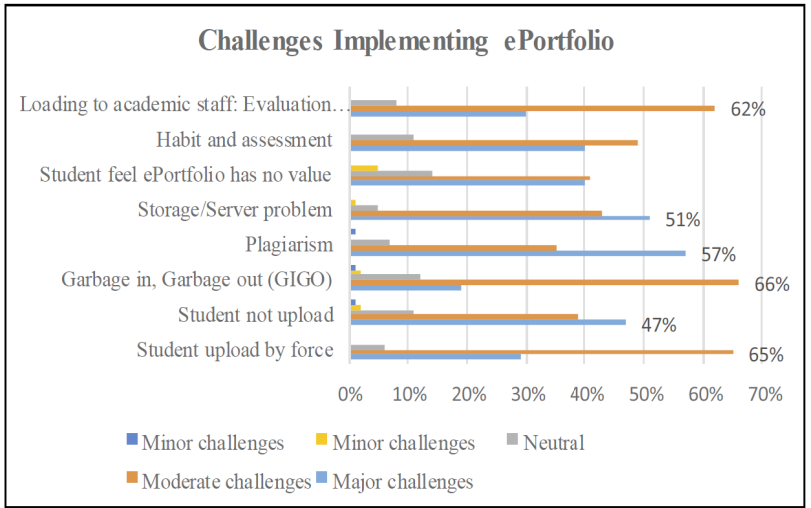

Figure 12. Challenges in Implementing ePortfolio in the Learning Process

\section{G. Challenges in Implementing ePortfolio}

Implementing ePortfolio in the learning process has several challenges. Figure 12 illustrates the major challenges as follows: plagiarism (57\%), storage or server problem $(51 \%)$, and students did not upload their learning material in the ePortfolio (47\%). Moderate challenges come from activities of garbage in and garbage out of learning materials that are uploaded in the ePortfolio $(66 \%)$, followed by student only uploading the learning material by force $(65 \%)$, and loading work to academic staff to evaluate ePortfolio (62\%). Other issues, such as creating the ePortfolio because of habit and assessment and students feel the ePortfolio has no value, are considered as moderate challenges but with a lower percentage. ePortfolio improves the independence of students through self-learning. Therefore, students must be mature and motivated to learn independently; otherwise, they may be left behind in the learning process. Ahn (2004) mentioned that the ePortfolio inspires students to be reflective when constructing their own ePortfolio. Therefore, frequent training must be provided by universities or institutions to encourage and motivate students to use the ePortfolio as part of learning.

\section{CONCLUSION}

The implementation of ePortfolio is very useful to improve the learning system at a higher education level. ePortfolio supports the ideology of creating a "balanced' student"; it not only facilitates the assessment of students holistically but also encourages students to learn new skills that are unavailable in the classroom, especially about Web 2.0 tools. All of these skills are normally acquired only by their experiences (i.e., learning by doing). To create an effective ePortfolio and obtain good grades, students must acquire such competency. Therefore, the implementation of ePortfolio can produce proactive students who participate in various activities in their learning.

The Google survey results indicate that the majority of the respondents give positive feedback on the development of ePortfolio as one of the holistic approaches to evaluate student's knowledge and skills. Thus, the comprehensive contents of ePortfolio must be developed. A good ePortfolio must have inclusive contents that meet selected important criteria to measure the academic achievement of students. Therefore, the integration of a suitable assessment method is equally important to determine the success of the ePortfolio system.

\section{ACKNOWLEDGMENT}

The authors would like to express our heartfelt thanks to Universiti Kebangsaan Malaysia [Pusat Citra Universiti (Citra UKM), Lestari Physical Development Research Group (LPhyD) and the Evolutionary and Sustainable Urban Living Research Group (EvoSUL)] for supporting this research. Credit also goes to various organizations, which facilitated the successful completion of this research.

\section{REFERENCES}

[1] T. Batson, "Situated Learning: A Theoretical Frame to Guide Transformational Change Using Electronic Portfolio Technology" in International Journal of ePortfolio, 2011, pp 1 (1): 107-114.

[2] W. Hall, "From Personal to Social and Back Again: A Review of Darren Cambridge's Eportfolios for Lifelong Learning and Assessment (Jossey-Bass, 2010)" in International Journal of ePortfolio, 2011, pp. 1(1): 115-117

[3] G. Brown., H. L. Chen \& A. Gordon, "The Annual AAEEBL Survey at Two: Looking Back and Looking Ahead" in International Journal of ePortfolio, 2012, pp 2 (2): 129-138.

[4] D. J. Goldsmith, "Enhancing learning and assessment through eportfolios: A collaborative effort in Connecticut" in New Directions for Student Services, 2007, pp. (119): 31-42.

[5] A. Shada, K. Kelly, R. Cox \& S. Malik, "Growing a New Culture of Assessment: Planting ePortfolios in the Metro Academies Program" in International Journal of ePortfolio. 2011, pp.1(1): 71-83.

[6] G. Lorenzo \& J. Ittelson (2005, June 2). An overview of eportfolios. Educause Learning Initiative, ELI Paper 1 [online]. Available: http://net.educause.edu/ir/library/pdf/ELI3001.pdf

[7] K. Ramirez, "ePerformance: Crafting, Rehearsing, and Presenting the ePortfolio Persona" in International Journal of ePortfolio, 2011, pp. 1(1): 1-9.

[8] S. Jarrott \& L. E. Gambrel, "The Bottomless File Box: Electronic Portfolios for Learning and Evaluation Purposes" in International Journal of ePortfolio, 2011, pp. 1(1): 85-94.

[9] C. E. Watson \& P. E. Doolittle, "ePortfolio Pedagogy, Technology, and Scholarship: Now and in the Future" in Educational Technology, 2011, pp. 51(5): 29-33.

[10] R. Tolley (2010, May 24). Garbage in, garbage out. [Online] Available: http://efoliointheuk.blogspot.com/2010/10/garbage-ingarbage-out.html

[11] K. Kelly \& R. Cox, "ePorticulture: Growing A New Culture of Assessment" in Cross-Cultural Interaction: Concepts, Methodologies, Tools and Applications (pp. 1623-1636). Hershey, PA: Information Science Reference, 2014. http://dx.doi.org/10.4018/9781-4666-4979-8.ch092

[12] Hart Research Associates, "It Takes More than a Major: Employer Priorities for College Learning and Student Success. An Online Survey among Employers Conducted On Behalf Of: The Association of American Colleges and Universities", Washington D.C.: Hart Research Associates, 2013.

[13] J. Whitworth, T. Deering, S. Hardy \& S. Jones, "Perceptions Regarding the Efficacy and Use of Professional Portfolios in the Employment of Teachers" in International Journal of ePortfolio, 2011, pp. 2 (1): 95-106.

[14] L. Pelliccione \& K. Dixon, "ePortfolios: Beyond assessment to empowerment in the learning landscape" in Hello! Where are you in the landscape of educational technology? Proceedings ascilite Melbourne, 2008, pp 750-760.

[15] L. Willis \& L. Wilkie, "Digital career portfolios: Expanding institutional opportunities" in Journal of Employment Counseling, 2009, pp. 46: 73-81.

[16] C. A. Buyarski \& C. M. Landis, "Using an ePortfolio to Assess the Outcomes of a First-Year Seminar: Student Narrative and Authentic Assessment" in International Journal of ePortfolio, 2014, pp. 4(1): 49-60.

[17] K. B. Yancey, "Electronic portfolios a decade into the twenty-first century: What we know, what we need to know" in Peer Review, 2009, pp. 11(1): 28-32. 
[18] J. D. Jenson, "Promoting Self-regulation and Critical Reflection Through Writing Students' Use of Electronic Portfolio" in International Journal of ePortfolio, 2011, pp. 1(1): 49-60.

[19] S. Peacock, S. Murray, A. Scott \& J. Kelly, "The Transformative Role of ePortfolios: Feedback in Healthcare Learning" in International Journal of ePortfolio, 2011, pp. 1(1): 33-48.

[20] E. S, Danowitz, "On the Right Track: Using ePortfolios as Tenure Files" in International Journal of ePortfolio, 2012, pp. 2(1): 113124.

[21] A. I. Che-Ani, N. M. Tawil, S. Johar, K. Ismail \& M. Z. AbdRazak, "Universiti Kebangsaan Malaysia Learning Contract Course: Experience and Performance of the First Cohort" in International Education Studies, 2014, pp. 7 (2): 1-9. http://dx.doi.org/10.5539/ies.v7n2p1

[22] J. Ahn, (2014. May 24). Electronic portfolios: Blending technology, accountability and assessment [online]. Available: http://thejournal.com/articles/16706

[23] X. Ma \& R. Rada, "Building a web-based accountability system in a teacher education program" in Interactive Learning Environments, 2005, pp. 13(1-2), 93-119.

[24] J. R. Young, “'E-portfolios' could give students a new sense of their accomplishments" in Chronicle of Higher Education, 2002, pp. 48(26), A31-A32.
[25] J. Turns, B. Sattler, M. Eliot, D. Kilgore \& K. Mobrand, "Preparedness Portfolios and Portfolio Studios" in International Journal of ePortfolio, 2012, pp. 2 (1): 1-13.

\section{AUTHORS}

S.R.H. Abd-Wahab is with the Faculty of Engineering and Built Environment, Universiti Kebangsaan Malaysia.

A. I. Che-Ani is with the Faculty of Engineering and Built Environment, Universiti Kebangsaan Malaysia and Pusat Citra Universiti, Universiti Kebangsaan Malaysia.

S. Johar is with the Faculty of Engineering and Built Environment, Universiti Kebangsaan Malaysia.

K. Ismail is with Pusat Citra Universiti, Universiti Kebangsaan Malaysia.

M. Z. Abd-Razak is with Pusat Citra Universiti, Universiti Kebangsaan Malaysia.

Submitted 28 July 2015. Published asresubmitted by the authors 23 December 2015. 